\title{
Association of moderate-to-vigorous physical activity with neck circumference in eight Latin American countries
}

Gerson Luis de Moraes Ferrari ${ }^{1,2^{*}}$, Irina Kovalskys ${ }^{3}$, Mauro Fisberg ${ }^{4,5}$, Georgina Gomez ${ }^{6}$, Attilio Rigotti ${ }^{7}$, Lilia Yadira Cortés Sanabria ${ }^{8}$, Martha Cecilia Yépez García ${ }^{9}$, Rossina Gabriella Pareja Torres ${ }^{10}$, Marianella Herrera-Cuenca ${ }^{11}$, Ioná Zalcman Zimberg ${ }^{12}$, Viviana Guajardo ${ }^{3}$, Michael Pratt ${ }^{13}$, Carlos Pires ${ }^{14}$, Dirceu Solé ${ }^{2}$ and on behalf of the ELANS Study Group

\begin{abstract}
Background: Physical activity is a cornerstone in the prevention and treatment of obesity. There are relatively few studies that explore the effect of accelerometer-determined moderate-to-vigorous physical activity (MVPA) on neck circumference (NC), most of them confined to single high-income countries. The present study investigated the association of accelerometer-determined MVPA with NC in adolescents and adults from eight Latin American countries, which are mostly upper-middle income countries.

Methods: The sample consisted of 2370 participants (47.8\% male) from the Latin American Study of Nutrition and Health, a multicenter cross-sectional nutrition and health surveillance study of a nationally representative sample from eight Latin American countries (Argentina, Brazil, Chile, Colombia, Costa Rica, Ecuador, Peru, and Venezuela). Times (min/day) in MVPA (defined as time accumulated at $\geq 1952$ activity counts/min) was assessed by ActiGraph GT3X+ accelerometer over 7 days. NC for adolescent was categorized as abnormal if circumference was $>34.5 \mathrm{~cm}$ for boys and $>31.25$ for girls, whereas for adults the cut-off points for abnormal were $>39 \mathrm{~cm}$ for men and $>35 \mathrm{~cm}$ women. Multilevel logistic models, including country and region as random effects and adjusted for sex, age, socioeconomic level, and educational level, were used to study the association between MVPA and NC.

Results: The average time of MVPA was 34.88 min/day, ranging from 31.16 in Venezuela to 40.27 in Chile. Concerning NC, $37.0 \%$ of the sample was classified as having elevated NC. Chile was the country with the highest percentage of people with elevated NC (56.9\%), and Colombia had the lowest percentage (24.8\%). Overall, the MVPA (min/day) was associated with elevated NC (OR $=0.994, C 195 \%=0.990-0.998)$. In Costa Rica and Peru, there were significant associations between MVPA and NC when analyzed by country.

Conclusions: The present study provided evidence of significant associations between MVPA and NC in adolescents and adults from Latin America, independent of sex, age, socioeconomic level, and educational level. This analysis of accelerometry data and NC represents the first examination of these associations in eight Latin America countries. Further research is required to understand the differences between countries in the observed associations.
\end{abstract}

Trial registration: ClinicalTrials.Gov NCT02226627. Retrospectively registered on August 27, 2014.

Keywords: Physical activity, Accelerometer, Neck circumference, Obesity, Body composition, Anthropometric

\footnotetext{
* Correspondence: gersonferrari08@yahoo.com.br

${ }^{1}$ Centro de Investigación en Fisiologia del Ejercicio-CIFE, Universidad Mayor,

José Toribio Medina, 29. Estacion Central, Santiago, Chile

${ }^{2}$ Disciplina de Alergia, Imunologia Clínica e Reumatologia do Departamento

de Pediatria, da Universidade Federal de São Paulo, São Paulo, Brazil

Full list of author information is available at the end of the article
}

(c) The Author(s). 2019 Open Access This article is distributed under the terms of the Creative Commons Attribution 4.0 International License (http://creativecommons.org/licenses/by/4.0/), which permits unrestricted use, distribution, and

reproduction in any medium, provided you give appropriate credit to the original author(s) and the source, provide a link to the Creative Commons license, and indicate if changes were made. The Creative Commons Public Domain Dedication waiver (http://creativecommons.org/publicdomain/zero/1.0/) applies to the data made available in this article, unless otherwise stated. 


\section{Background}

The prevalence of overweight and obesity is a major global health concern [1] that now extends beyond highincome nations to low- and middle- income nations [2]. Obesity is positively associated with developing several chronic disorders, including cardiovascular disease (CVD; i.e., type II diabetes, insulin resistance, hypertension, and cholesterol levels), mortality and life expectancy, and can be reduced by adherence to a healthy lifestyle [3-6]. Consequently, early detection of weight gain is crucial to preventing adverse long-term effects on individuals' lifestyle [5].

Central, visceral or subcutaneous fat, is strongly associated with the risk of developing several chronic disorders. It has been discussed in the literature that other deposits of fat may also contribute to the CVD [7]. Neck circumference $(\mathrm{NC})$ has been associated with waist circumference (WC), body mass index (BMI) and with components of metabolic syndrome [8-12]. NC is a simple and valid measure of fat mass, more practicable and may have better association with triglycerides, HOMA, HDL-C than BMI and WC [9].

Physical activity, a cornerstone in the prevention and treatment of obesity and CVD, has been shown to be inversely related to fatness $[13,14]$. The prevalence of physical inactivity in Latin America (LA) was reported the highest worldwide [15] and ranked fifth as a risk factor for mortality in the Southern Cone of LA [16]. LA is the most urbanized region in the world $(80 \%$ of its population lives in cities) [17] and has rising prevalence of obesity, chronic diseases, and physical inactivity [18, 19]. Obesity and physical inactivity are now especially important public health challenges in LA [20].

The objective assessment of moderate-to-vigorous physical activity (MVPA) using accelerometers has become more common practice in research originating from high-income countries [14, 21]. In contrast, given the cost associated with using objective measures like accelerometers and the lack of research in this field in most LA countries [22], there are relatively few studies using this technology in LA countries [23]. To our knowledge, there has been no examination of the association between objective assessment of MVPA using accelerometers with $\mathrm{NC}$ in a nationally representative sample from LA. Thus, the purpose of this article is to investigate the association of accelerometer-determined MVPA with $\mathrm{NC}$ in adolescents and adults from eight LA countries.

\section{Methods}

Study design and participants.

The Latin American Study of Nutrition and Health (Estudio Latinoamericano de Nutrición y Salud; ELANS) is a cross-sectional, multinational representative sample conducted in eight LA countries representing a total of
9218 individuals, aged 15-65 years, stratified by geographical location, gender, age, and socioeconomic level (SEL). The overarching ELANS protocol was approved by the Western Institutional Review Board (\#20140605) and is registered at Clinical Trials (\#NCT02226627). Additional site-specific protocols were also approved by the ethical review boards of the participating institutions. All participants provided informed consent/assent for participation in their country-level study. The rationale and design of the study are available in more detail elsewhere [24].

Accelerometer The Actigraph GT3 $x+$ accelerometer (ActiGraph, Ft. Walton Beach, United States) was used to objectively monitor MVPA in $29.6 \%$ of the total sample. The accelerometer was worn around their waist on a belt for 7 consecutive days and the participants were instructed to wear the instrument.

Participants were encouraged to wear the accelerometer at least $12 \mathrm{~h} /$ day for at least 7 days of wear time following the removal of sleep, showering or swimming time [25, 26]. The minimal amount of accelerometer data that was considered acceptable for analytical purposes was 5 days (including at least one weekend day) with at least $10 \mathrm{~h}$ /day of waking wear time. After exclusion of the nocturnal sleep period time, waking nonwear time was defined as any sequence of at least 60 consecutive minutes of zero activity counts. Data were collected at a sampling rate of $30 \mathrm{~Hz}$ and downloaded in periods of $60 \mathrm{~s}$ [27].

On the eighth day of data collection, the research team went to the house of the participants to remove accelerometers. The research team confirmed that the data were completed using the latest version of Actilife software (version 6.0; ActiGraph, Pensacola, FL) available.

Activity cut-points were based on Freedson et al. [28] for counts/min. The cut-points capture the sporadic nature of activity and provide the best classification accuracy among the currently available cut-points for physical activity. Specifically, moderate physical activity was defined as time accumulated at $\geq 1952-5724$ activity counts/min, $\geq 5725$ activity counts/min for vigorous physical activity, and $\geq 1952$ activity counts/min for MVPA [28] not including the sleep period and non-wear time. The Actigraph cut-points that were used in the present study were derived from studies of a previous model of the Actigraph [29-31]. Reliability and validity of accelerometers have been documented extensively [29-31].

\section{Neck circumference}

$\mathrm{NC}$ (in centimeters) was measured at the point just below the larynx (thyroid cartilage) and perpendicular to the long axis of the neck (with the tape line in the front 
of the neck at the same height as the tape line at the back of the neck) using an inelastic tape measure [32]. Each measurement was repeated twice to ensure accuracy, and the average was used for the analyses. If the two readings differed by more than the previously established set point $(0.5 \mathrm{~cm}$ for $\mathrm{NC})$, then a third measurement was taken. All three measurements were recorded, and the outlier was excluded during the data cleaning process. Different cut-points of NC were used to classify central obesity in adolescents and adults $[8,33]$. NC for adolescent was categorized as abnormal if circumference was > $34.5 \mathrm{~cm}$ for boys and $>31.25$ for girls [8], whereas for adults the cut-off points for abnormal were $>39 \mathrm{~cm}$ for men and $>35 \mathrm{~cm}$ women [33]. These cut-points are probably the best to determine individuals with central obesity and metabolic syndrome $[8,33]$. The interviewers were trained to collect all measurements by certified nutritionists/dietitians who simultaneously operated as supervisors of the fieldwork.

\section{Sociodemographic and SEL variables}

A questionnaire was used to collect information about demographics such as age (expressed in years), gender, years of education, race/ethnicity, and marital status. SEL was also evaluated by questionnaire using a format based on the national indexes used in each country [3441]. SEL data were divided into three strata (low, medium, and high). Individuals were asked about sex, age, and education level (equivalent to non-formal education or primary school), middle (equivalent to secondary school), and high (equivalent to technical or university degree). These sociodemographic variables were included as covariates in all statistical models.

Statistical analyses Statistical analyses were carried out using the $\mathrm{R}$ software [42]. A Kolmogorov-Smirnov test was applied to evaluate the data distribution. Mean, standard deviation, and frequencies were computed to describe the variables studied.

Multilevel logistic models, including country and region as random effects and adjusted for sex, age, SEL, and educational level, were used to study the association between MVPA (min/day) and NC (dependent variable: normal or elevated values). Multilevel models were carried out using the $\mathrm{R}$ package lme4 [43]. A significance level of $5 \%$ was set.

\section{Results}

The sample included 2370 participants, aged from 15 to 65 years old $(M=36.6, S D=14.2)$, who used the accelerometer, which represented $29.6 \%$ of the total sample of the ELANS project $(n=9218)$. There were no significant differences between the participants who used the accelerometer and those who did not concerning sex ( $p=$
$0.937)$, SEL $(p=0.501)$, or educational level $(p=0.235)$. However, the distribution by age group was different $(p=0.018)$; the participants with accelerometer were slightly older.

The participants used the accelerometer between 5 and 7 days. On average, the accelerometer was used for $15.3 \mathrm{~h} /$ day, which represented a total time of $100.7 \mathrm{~h}$. This time ranged from $14.8 \mathrm{~h}$ /day in Costa Rica to 15.8 $\mathrm{h} /$ day in Peru (Supplementary material 1).

There were slightly more female $(52.2 \%)$ than male (47.8\%) participants. About 2 out of 3 participants were aged from 20 to 49 years old (65.8\%). About half (51.2\%) were from low SEL, and more than half (60.1\%) had a basic educational level or lower. Only $10.0 \%$ were from a high SEL, and $10.2 \%$ had a university degree (Table 1 ).

The average time of MVPA was $34.88 \mathrm{~min} /$ day, ranging from 31.16 in Venezuela to 40.27 in Chile. Concerning $\mathrm{NC}, 37.0 \%$ of the full sample was classified as having elevated NC. Chile was the country with the highest percentage of people with elevated NC with more than half (56.9\%), and Colombia had the lowest percentage (24.8\%) (Table 2).

Tables 3 and 4 present the results of the multilevel logistic regression analysis describing the association between MVPA and NC. The effect of daily MVPA (min/ day) on NC, considering two hierarchical levels (country and region) and adjusted for sex, age, SEL, and educational level, is presented in Table 3. Overall, the increase of one min/day of MVPA is associated with a decrease of $0.6 \%$ in the chance of having an elevated $\mathrm{NC}(\mathrm{OR}=$ 0.994 , CI95\% $=0.990-0.998, p=0.003)$. The association was similar across all countries but only significant in two: Costa Rica (OR $=0.980, \mathrm{CI} 95 \%=0.964-0.997, p=$ $0.024)$ and Peru (OR $=0.989, \mathrm{CI} 95 \%=0.980-0.999, p=$ 0.031) (Table 4).

\section{Discussion}

This study aimed to investigate the association of accelerometer-determined MVPA with NC in adolescents and adults from eight LA countries. The average time of MVPA was $34.88 \mathrm{~min} /$ day, and $37.0 \%$ of the full sample was classified as having elevated NC. Overall, the increase of one min/day of MVPA is associated with a decrease of $0.6 \%$ in the chance of having an elevated NC. When analyzed by country, the association was similar across all countries but only significant in Costa Rica and Peru. The effect significance of MVPA (min/ day) on NC, considering two hierarchical levels (country and region), was adjusted for sex, age, SEL, and education level.

Latin America is the most urbanized region in the world ( $80 \%$ of Latin Americans live in cities) with demographic and epidemiological changes. Furthermore, high population density, disorganized transit systems, traffic 
Table 1 Descriptive analysis (\%) of sample profile concerning sex, age group, socioeconomic, and educational level of adolescents and adults from eight Latin America countries

\begin{tabular}{|c|c|c|c|c|c|c|c|c|c|c|c|c|c|}
\hline \multirow[t]{2}{*}{ Country } & \multirow[t]{2}{*}{$\mathrm{N}$} & \multicolumn{2}{|c|}{ Sex (\%) } & \multicolumn{4}{|c|}{ Age group (\%) } & \multicolumn{3}{|c|}{ Socioeconomic level (\%) } & \multicolumn{3}{|c|}{ Educational level (\%) } \\
\hline & & Male & Female & $15-19$ & $20-34$ & $35-49$ & $50-65$ & Low & Medium & High & Basic or lower & High school & University degree \\
\hline Argentina & 293 & 44.4 & 55.6 & 10.6 & 30.7 & 33.1 & 25.6 & 53.9 & 41.3 & 4.8 & 73.7 & 23.9 & 2.4 \\
\hline Brazil & 563 & 46.2 & 53.8 & 11.0 & 36.2 & 29.0 & 23.8 & 41.7 & 50.4 & 7.8 & 44.9 & 46.7 & 8.3 \\
\hline Chile & 297 & 46.5 & 53.5 & 10.8 & 36.7 & 27.6 & 24.9 & 41.4 & 47.5 & 11.1 & 61.6 & 23.6 & 14.8 \\
\hline Colombia & 339 & 49.9 & 50.1 & 10.0 & 35.7 & 27.4 & 26.8 & 64.0 & 31.0 & 5.0 & 66.4 & 22.1 & 11.5 \\
\hline Costa Rica & 273 & 47.6 & 52.4 & 13.6 & 35.5 & 30.0 & 20.9 & 34.1 & 54.2 & 11.7 & 83.9 & 11.4 & 4.8 \\
\hline Ecuador & 268 & 50.4 & 49.6 & 13.4 & 40.3 & 29.9 & 16.4 & 44.8 & 40.7 & 14.6 & 79.1 & 11.9 & 9.0 \\
\hline Peru & 330 & 48.2 & 51.8 & 14.5 & 39.7 & 24.8 & 20.9 & 47.0 & 30.0 & 23.0 & 20.6 & 67.6 & 11.8 \\
\hline Venezuela & 367 & 49.9 & 50.1 & 13.4 & 42.2 & 27.8 & 16.6 & 80.9 & 14.2 & 4.9 & 69.2 & 13.1 & 17.7 \\
\hline Full sample & 2730 & 47.8 & 52.2 & 12.1 & 37.2 & 28.6 & 22.2 & 51.2 & 38.8 & 10.0 & 60.1 & 29.7 & 10.2 \\
\hline
\end{tabular}

congestion, pronounced income inequality, and important and rapid nutritional transition are some of the characteristics of LA. However, one point stands out: the marked increase in the prevalence of obesity and chronic diseases in nearly all of LA [44-46]. More than $20 \%$ of population from LA, including youth are overweight or obese, and the indices has increased to a greater scale specifically in Mexico, Argentina, and Chile. [47] and in 2030 , up to $81.9 \%$ of the LA adult population could be either overweight or obese [48]. This is the first study to report NC for a representative sample of LA adolescents and adults from an urban setting; therefore, the only possible comparison was against previous reports that used other anthropometric methods. The prevalence of obesity (BMI $\geq 30 \mathrm{~kg} / \mathrm{m}^{2}$ ) in São Paulo, Brazil, was more than $23 \%$ and in Santiago, Chile, was more than 31\% [49]. In our study, we found $28.1 \%$ elevated NC in Brazil and $56.7 \%$ in Chile.

Table 2 Descriptive analysis of moderate-to-vigorous physical activity (Mean and SD) and neck circumference (frequency and $\%)$ of adolescents and adults from eight Latin America countries $(n=2730)$

\begin{tabular}{llll}
\hline Country & MVPA & \multicolumn{2}{l}{ Neck circumference } \\
\cline { 3 - 4 } & $\begin{array}{l}\text { Min/day } \\
\text { Mean (SD) }\end{array}$ & $\begin{array}{l}\text { Normal } \\
\mathrm{n}(\%)\end{array}$ & $\begin{array}{l}\text { Elevated } \\
\mathrm{n}(\%)\end{array}$ \\
\hline Argentina & $32.81(22.63)$ & $169(57.7 \%)$ & $124(42.3 \%)$ \\
Brazil & $33.37(24.63)$ & $405(71.9 \%)$ & $158(28.1 \%)$ \\
Chile & $40.27(23.66)$ & $128(43.1 \%)$ & $169(56.9 \%)$ \\
Colombia & $34.84(24.63)$ & $255(75.2 \%)$ & $84(24.8 \%)$ \\
Costa Rica & $32.41(28.19)$ & $149(54.6 \%)$ & $124(45.4 \%)$ \\
Ecuador & $40.04(30.58)$ & $188(70.1 \%)$ & $80(29.9 \%)$ \\
Peru & $36.43(26.60)$ & $212(64.2 \%)$ & $118(35.8 \%)$ \\
Venezuela & $31.16(21.91)$ & $213(58.0 \%)$ & $154(42.0 \%)$ \\
Full sample & $34.88(25.40)$ & $1719(63.0 \%)$ & $1011(37.0 \%)$ \\
\hline
\end{tabular}

MVPA moderate-to-vigorous physical activity
The prevalence of overweight and obesity is increasing in LA, and high rate of body fat is a risk factor for increase closely associated factors (i.e., chronic disease, hypertension and type II diabetes) [50]. Epidemiologic study have identified each $5 \mathrm{~kg} / \mathrm{m}^{2}$ higher BMI was associated, on average, with $30 \%$ higher overall mortality, specifically $40 \%$ for vascular diseases; $60-120 \%$ for diabetes; $10 \%$ for cancer; and $20 \%$ for respiratory diseases and all other causes [51].

NC provide high values in prediction of distribution of upper-body subcutaneous, is valid marker and the data collection is simple to execute [52-56]. BMI and others anthropometric indicators have long been suggested of defining the overweight and obesity of person [57]. Upper body fat distribution has been considered a risk factor of CVD. It has been reported that free fatty acids are released in larger proportion from upper body subcutaneous fat than lower body subcutaneous fat [58]. Moreover, NC has been used as an index for such an adverse risk profile [59, 60]. Joshipura et al. [9] showed that NC was significantly associated with metabolic factors, including components of metabolic syndrome (hypertension, triglycerides, glucose $\geq 100$, HOMA-IR); the magnitude of the associations is modest, ranging from 0.45-0.66. Importantly, compared to traditional anthropometric measures such as BMI, WC, and body fat percent, NC showed higher significant association with prediabetes and with HDL-C, [9].

This is the first study reporting significant association of accelerometer-determined MVPA with $\mathrm{NC}$ of nationally representative samples from urban populations from LA countries (Argentina, Brazil, Chile, Colombia, Costa Rica, Ecuador, Peru, and Venezuela). This study supports previous research that has shown negative relationships between accelerometer-determined MVPA and body composition variables $[61,62]$. Our results corroborate those of Van Dyck et al. [62], who reported significant associations of accelerometer-determined MVPA with 
Table 3 Multilevel logistic models for moderate-to-vigorous physical activity (min/day) with neck circumference of adolescents and adults from eight Latin America countries-full sample $(n=2730)$

\begin{tabular}{lll}
\hline Independent variables & Dependent variable: Neck circumference (normal and elevated) \\
\cline { 2 - 3 } & OR (Cl95\%) & $p$ \\
\hline MVPA (min/day) & $0.994(0.990,0.998)$ & 0.003 \\
Sex female (vs. male) & $0.739(0.624,0.875)$ & $<0.001$ \\
Age (years) & $1.013(1.007,1.019)$ & $<0.001$ \\
Socioeconomic level medium (vs. low) & $1.143(0.947,1.380)$ & 0.164 \\
Socioeconomic level high (vs. low) & $1.003(0.731,1.378)$ & 0.983 \\
Educational level high school (vs. basic or lower) & $0.756(0.613,0.932)$ & 0.009 \\
Educational level university degree (vs. basic or lower) & $0.780(0.573,1.062)$ & 0.114
\end{tabular}

Multilevel logistic model with three levels (individual, region, country)

MVPA moderate-to-vigorous physical activity, OR odds ratio, C195 95\% confidence interval

BMI in adults from 12 countries, independent of country and SEL. Our study showed significant association between MVPA and NC, independent of sex, age, SEL, and educational level. Both our study and the Van Dick et al. [62] study used the cut-point of $\geq 1952 \mathrm{cpm}$ for MVPA [28]. Higher levels of physical activity may have important additional beneficial effects on fitness or other health outcomes [63]. However, one must keep in mind that the present results are cross-sectional; therefore, no true dose-response relationships can be assumed.

Table 4 presents the results of the multi-level logistic regression analysis describing the significant association between MVPA and NC for Costa Rica $(\mathrm{OR}=0.980$, $\mathrm{CI} 95 \%=0.964-0.997)$ and Peru (OR $=0.989, \mathrm{CI} 95 \%=$ 0.980-0.999), considering two hierarchical levels (country and region) and adjusted for sex, age, SEL, and educational level. One conclusion from these results is that different patterns of MVPA are associated with high

Table 4 Multilevel logistic models for moderate-to-vigorous physical activity (min/day) with neck circumference of adolescents and adults from eight Latin America countries-in each country $(n=2730)$

\begin{tabular}{lll}
\hline Countries & \multicolumn{2}{l}{$\begin{array}{l}\text { Dependent variable } \\
\text { Neck circumference (normal and elevated) }\end{array}$} \\
\cline { 2 - 3 } & OR (Cl95\%) & $p$ \\
\hline MVPA (min/day) & & 0.490 \\
Argentina & $0.996(0.984,1.008)$ & 0.214 \\
Brazil & $0.990(0.975,1.006)$ & 0.846 \\
Chile & $0.998(0.982,1.015)$ & 0.105 \\
Colombia & $0.990(0.979,1.002)$ & 0.024 \\
Costa Rica & $0.980(0.964,0.997)$ & 0.643 \\
Ecuador & $0.997(0.984,1.010)$ & 0.031 \\
Peru & $0.989(0.980,0.999)$ & 0.178 \\
Venezuela & $0.990(0.976,1.004)$ & \\
\hline
\end{tabular}

Multilevel logistic models, one for each country, with two levels (individual, region), adjusted for sex, age, socioeconomic level, and educational level MVPA moderate-to-vigorous physical activity, OR odds ratio, C195 95\% confidence interval prevalence estimates of elevated $\mathrm{NC}$, so countries could tailor physical activity and obesity promotion strategies to local infrastructure, available programs, and culture. The results shows the variety and diversity of countries from LA, and, thus, the need to better understand these realities for to expand healthy eating habits in LA [64, 65]. For example, Peruvian people have increased their BMI during fifteen years (1996-2011), and more than global female trend rate [66]. Worldwide, adult BMI has increased by $0.4-0.5 \mathrm{~kg} / \mathrm{m}^{2}$ per decade [66]. Moreover, adult obesity levels have been augmented from 6.4 to $12.0 \%$ [67]. In addition, sedentary activities and physical inactivity due to rapid urbanization have been contributing to escalating levels of over-nutrition [45]. In a region experiencing escalating rates of obesity and inactivity, there is an opportunity to promote effective interventions as interdisciplinary strategies (i.e., coordination between health, sports and education departments) to increase physical activity, healthy eating habits and prevent noncommunicable diseases.

The results of the study may not be directly generalizable to other countries. Nevertheless, no study has evaluated the accelerometer-determined MVPA and $\mathrm{NC}$ of adolescent and adult populations in LA using a standardized methodology across a consortium of several participating countries. The present study had several strengths: the number of participants; comparable data collection protocols; the inclusion of objective data on physical activity makes ELANS a unique Latin American data source. To date, most studies in low- and middle-income countries have had to rely on selfreported physical activity data $[68,69]$; and it expands the existing literature by reporting the association of physical activity with NC. However, the ELANS employed a cross-sectional design, the cut-off point of counts/min for classifying the intensity of physical activity (light, moderate and vigorous) was the same for adolescents and adults and to the number of participants that did not have any information on the MVPA. 


\section{Conclusions}

When analyzing all countries together, the present study provided evidence of significant associations between MVPA and NC in adolescents and adults from LA, independent of sex, age, SEL, and educational level. When analyzed separately by country, only Costa Rica and Peru showed significant association between MVPA and NC.

This examination of accelerometry data and NC characterizes the primary investigation of these associations in eight LA countries. Further prospective study is need to assess $\mathrm{NC}$ can substitute others anthropometrics methods to better elucidate of obesity correlates and to understand the variability observed in urban regions in the detected relations.

\section{Abbreviations}

BMI: Body mass index; C195\%: 95\% Confidence interval; CVD: Cardiovascular disease; ELANS: Latin American Study of Nutrition and Health / Estudio Latinoamericano de Nutrición y Salud; LA: Latin America; M: Mean; MVPA: Moderate-to-vigorous physical activity; NC: Neck circumference; OR: Odds ratio; SD: Standard deviation; SEL: Socioeconomic level; WC: Waist circumference

\begin{abstract}
Acknowledgments
We would like to thank the following individuals at each of the participating sites who made substantial contributions to the ELANS: Luis A. Moreno, Beate Lloyd, Brenda Lynch, Mariela Jauregui, Alejandra Guidi, Luis Costa, and Regina Mara Fisberg.

The following are members of ELANS Study Group: Chairs: Mauro Fisberg and Irina Kovalskys; Co-chair: Georgina Gómez Salas; Core Group members: Attilio Rigotti, Lilia Yadira Cortés Sanabria, Georgina Gómez Salas, Martha Cecilia Yépez García, Rossina Gabriella Pareja Torres, and Marianella HerreraCuenca; Steering Committee: Berthold Koletzko, Luis A. Moreno, Michael Pratt, and Katherine L. Tucker; Project Managers: Viviana Guajardo and Ioná Zalcman Zimberg; International Life Sciences Institute-Argentina: Irina Kovalskys, Viviana Guajardo, María Paz Amigo, Ximena Janezic, and Fernando Cardini; Universidad I Salud: Myriam Echeverry and Martin Langsman; Instituto Pensi-Hospital Infantil Sabara-Brazil: Mauro Fisberg, loná Zalcman Zimberg, and Natasha Aparecida Grande de França; Pontificia Universidad Católica de Chile: Attilio Rigotti, Guadalupe Echeverría, Leslie Landaeta, and Óscar Castillo; Pontificia Universidad Javeriana-Colombia: Lilia Yadira Cortés Sanabria, Luz Nayibe Vargas, Luisa Fernanda Tobar, and Yuri Milena Castillo; Universidad de Costa Rica: Georgina Gómez Salas, Rafael Monge Rojas, and Anne Chinnock; Universidad San Francisco de Quito-Ecuador: Martha Cecilia Yépez García, María Elisa Herrera Fontana, Mónica Villar Cáceres, and María Belén Ocampo; Instituto de Investigación Nutricional-Perú: Rossina Pareja Torres, María Reyna Liria, Krysty Meza, Mellisa Abad, and Mary Penny; Universidad Central de Venezuela: Marianella Herrera-Cuenca, Maritza Landaeta, Betty Méndez, Maura Vasquez, Omaira Rivas, Carmen Meza, Servando Ruiz, Guillermo Ramirez, and Pablo Hernández; Statistical advisor: Alexandre D.P. Chiavegatto Filho; Accelerometry analysis: Priscila Bezerra Gonçalves and Claudia Alberico; Physical activity advisor: Gerson Luis de Moraes Ferrari.
\end{abstract}

\section{Authors' contributions}

GLMF conceived, designed, and helped to write and revise the manuscript; IK was responsible for coordinating the study and contributed to the intellectual content; MF was responsible for coordinating the study and contributed to the intellectual content and helped to write and revise the manuscript; GGS interpreted the data, helped to write and revise the manuscript, and helped implement the study; AR interpreted the data, helped to write and revise the manuscript, and helped implement the study; LYCS interpreted the data, helped to write and revise the manuscript, and helped implement the study; MCYG interpreted the data, revised the manuscript, and helped implement the study; RGPT interpreted the data, helped to write and revise the manuscript, and helped implement the study; $\mathrm{MH}-\mathrm{C}$ interpreted the data, revised the manuscript, and helped implement the study; IZZ was responsible for coordinating the study, interpreted the data, and revised the manuscript; VG interpreted the data, revised the manuscript, and helped implement the study; MP interpreted the data, revised the manuscript, and helped implement the study; CP interpreted the data and helped to write and revise the manuscript; DS interpreted the data and helped to write and revise the manuscript. All authors contributed to the study design, critically reviewed the manuscript, and approved the final version. All authors contributed to the study design, critically reviewed the manuscript, and approved the final version.

\section{Funding}

The ELANS was supported by a scientific grant from the Coca Cola Company and support from the Ferrero, Instituto Pensi/Hospital Infantil Sabara, International Life Science Institute of Argentina, Universidad de Costa Rica, Pontificia Universidad Católica de Chile, Pontificia Universidad Javeriana, Universidad Central de Venezuela/Fundación Bengoa, Universidad San Francisco de Quito, and Instituto de Investigación Nutricional de Peru. The founding sponsors had no role in study design; data collection, analyses, or interpretation; writing of the manuscript; or the decision to publish the results. This study is registered at https://clinicaltrials.gov/ct2/show/ NCT02226627?term=mauro+fisberg\&rank=1 (No. NCT02226627).

\section{Availability of data and materials}

The dataset used and analysed during the current study are available from the corresponding author on reasonable request.

\section{Ethics approval and consent to participate}

This study was conducted according to the guidelines laid down in the Declaration of Helsinki and all procedures involving human subjects/patients and each site specific protocol was also approved by the ethical review boards of the participating institutions. The overarching ELANS protocol was approved by the Western Institutional Review Board (\#20140605) and is registered at Clinical Trials (\#NCT02226627).

Argentina: Comité de ética de la Asociación Médica Argentina; Brazil: Comité de ética do Instituto Pensi - Fundação José Luiz Setubal - Hospital Infantil Sabara; Chile: Comité de ético científico de la Facultad de Medicina de la Pontificia Universidad Católica de Chile; Colombia: Comité de Investigación y ética de la Faculdade de Ciencias de la Pontificia Universidad Javeriana; Costa Rica: Comité ético científico de la Vicerrectoría de Investigación de La Universidad de Costa Rica; Ecuador: Comité de Bioética Universidad de San Francisco de Quito; Peru: Comité Institucional de ética del Instituto de Investigación Nutricional; Venezuela: Comisión de Bioética de la Escuela de Antropología de la Universidad Central de Venezuela.

An document provided a short description of the purpose of the survey, confidentiality practices, contact information, and a link to the survey. Participants were considered consented once they read the document and signed to the survey. Informed assent was obtained from every adolescents and all parents and/or legal guardians signed an informed consent. All participants signed a written informed consent/assent before commencement of the study. Participants' confidentiality for the pooled data was maintained using numeric identification codes rather than names. All data transfer was done with a secure file sharing system.

\section{Consent for publication}

Not applicable.

\section{Competing interests}

All authors declare that they have no competing interests.

\footnotetext{
Author details

${ }^{1}$ Centro de Investigación en Fisiologia del Ejercicio-CIFE, Universidad Mayor, José Toribio Medina, 29. Estacion Central, Santiago, Chile. ${ }^{2}$ Disciplina de Alergia, Imunologia Clínica e Reumatologia do Departamento de Pediatria, da Universidade Federal de São Paulo, São Paulo, Brazil. ${ }^{3}$ Commitee of Nutrition and WellbeingInternational Life Science Institute, Buenos Aires, Argentina. ${ }^{4}$ Instituto Pensi, Fundação José Luiz Egydio Setubal, Hospital Infantil Sabará, São Paulo, Brazil. ${ }^{5}$ Departamento de Pediatria, da Universidade Federal de São Paulo, São Paulo, Brazil. ${ }^{6}$ Departamento de Bioquímica, Escuela de Medicina, Universidad de Costa Rica, San José, Costa Rica. ${ }^{7}$ Centro de Nutrición Molecular y Enfermedades Crónicas, Departamento de Nutrición, Diabetes y Metabolismo, Escuela de Medicina, Pontificia Universidad Católica, Santiago, Chile. ${ }^{8}$ Departamento de Nutrición y
} 
Bioquímica, Pontificia Universidad Javeriana, Bogotá, Colombia. ${ }^{9}$ Colégio de Ciencias de la Salud, Universidad San Francisco de Quito, Quito, Ecuador. ${ }^{10}$ Instituto de Investigación Nutricional, La Molina, Lima, Peru. ${ }^{11}$ Centro de Estudios del Desarrollo, Universidad Central de Venezuela/Fundación Bengoa, Caracas, Venezuela. ${ }^{12}$ Departamento de Psicobiologia, Universidade Federal de São Paulo, São Paulo, Brazil. ${ }^{13}$ Institute for Public Health, University of California San Diego, La Jolla, CA, USA. ${ }^{14}$ Centre for Mathematics of the University of Trás-OS-Montes e Alto Douro (CM-UTAD), Vila Real, Portugal.

\section{Received: 23 October 2018 Accepted: 11 June 2019}

\section{Published online: 24 June 2019}

\section{References}

1. Wang YC, MCPherson K, Marsh T, Gortmaker SL, Brown M. Health and economic burden of the projected obesity trends in the USA and the UK. Lancet. 2011;378:815-25.

2. Gupta N, Goel K, Shah P, Misra A. Childhood obesity in developing countries: epidemiology, determinants, and prevention. Endocr Rev. 2012;33:48-70.

3. Klop B, Elte JW, Cabezas MC. Dyslipidemia in obesity: mechanisms and potential targets. Nutrients. 2013;5:1218-40.

4. Leggio M, Lombardi M, Caldarone E, Severi P, D'Emidio S, Armeni M, et al. The relationship between obesity and hypertension: an updated comprehensive overview on vicious twins. Hypertens Res. 2017;40:947-63.

5. Umer A, Kelley GA, Cottrell LE, Giacobbi P Jr, Innes KE, Lilly CL. Childhood obesity and adult cardiovascular disease risk factors: a systematic review with meta-analysis. BMC Public Health. 2017;17:683.

6. Li Y, Pan A, Wang DD, Liu X, Dhana K, Franco OH, et al. Impact of healthy lifestyle factors on life expectancies in the US population. Circulation. 2018; 138(4):345-55.

7. Fox CS, Massaro JM, Hoffmann U, Pou KM, Maurovich-Horvat P, Liu CY, et al. Abdominal visceral and subcutaneous adipose tissue compartments: association with metabolic risk factors in the Framingham heart study. Circulation. 2007;116:39-48.

8. Ferretti Rde L, Cintra Ide P, Passos MA, de Moraes Ferrari GL, Fisberg M. Elevated neck circumference and associated factors in adolescents. BMC Public Health. 2015;15:208.

9. Joshipura K, Munoz-Torres F, Vergara J, Palacios C, Perez CM. Neck circumference may be a better alternative to standard anthropometric measures. J Diabetes Res. 2016;2016:6058916.

10. Baena CP, Lotufo PA, Fonseca MG, Santos IS, Goulart AC, Bensenor IM. Neck circumference is independently associated with cardiometabolic risk factors: crosssectional analysis from ELSA-Brasil. Metab Syndr Relat Disord. 2016;14:145-53.

11. Dai $Y$, Wan $X, L i X$, Jin $E, L i X$. Neck circumference and future cardiovascular events in a high-risk population-a prospective cohort study. Lipids Health Dis. 2016;15:46.

12. Morais AA, Morais UAB, Soares MMS, Romano MCC, Lamounier JA. Neck circumference in adolescents and cardiometabolic risk: a sistematic review. Rev Assoc Med Bras (1992). 2018:64:54-62.

13. Kanejima Y, Kitamura M, Izawa KP. Self-monitoring to increase physical activity in patients with cardiovascular disease: a systematic review and meta-analysis. Aging Clin Exp Res. 2019;31:163-73.

14. Matthews CE, Keadle SK, Troiano RP, Kahle L, Koster A, Brychta R, et al. Accelerometer-measured dose-response for physical activity, sedentary time, and mortality in US adults. Am J Clin Nutr. 2016;104:1424-32.

15. Hallal PC, Andersen LB, Bull FC, Guthold R, Haskell W, Ekelund U. Lancet physical activity series working group. Global physical activity levels: surveillance progress, pitfalls, and prospects. Lancet. 2012;380:247-57.

16. Institute for Health Metrics and Evaluation. 2013. http://www. healthmetricsandevaluation.org/gbd/visualizations/gbd-arrow-diagram. Accessed 22 June 2018.

17. United Nations, Department of Economic and Social Affairs, Population Division. World population prospects: The 2011 revision. New York; 2012.

18. Barreto SM, Miranda JJ, Figueroa JP, Schmidt MI, Munoz S, Kuri-Morales PP, Silva JB Jr. Epidemiology in Latin America and the Caribbean: current situation and challenges. Int J Epidemiol. 2012;41:557-71.

19. Hoehner CM, Soares J, Parra Perez D, Ribeiro IC, Joshu CE, Pratt M, et al. Physical activity interventions in Latin America: a systematic review. Am J Prev Med. 2008;34:224-33.

20. Corvalan C, Garmendia ML, Jones-Smith J, Lutter CK, Miranda JJ, Pedraza LS, Popkin BM, Ramirez-Zea M, Salvo D, Stein AD. Nutrition status of children in Latin America. Obes Rev. 2017;18(Suppl 2):7-18.
21. Jefferis BJ, Parsons TJ, Sartini C, Ash S, Lennon LT, Wannamethee SG, Lee IM, Whincup PH. Does duration of physical activity bouts matter for adiposity and metabolic syndrome? A cross-sectional study of older British men. Int J Behav Nutr Phys Act. 2016;13:36.

22. Salvo D, Reis RS, Sarmiento OL, Pratt M. Overcoming the challenges of conducting physical activity and built environment research in Latin America: IPEN Latin America. Prev Med. 2014;69(Suppl 1):S86-92.

23. Ferrari GL, Oliveira LC, Araujo TL, Matsudo V, Barreira TV, Tudor-Locke C, Katzmarzyk P. Moderate-to-vigorous physical activity and sedentary behavior: independent associations with body composition variables in Brazilian children. Pediatr Exerc Sci. 2015;27:380-9.

24. Fisberg M, Kovalskys I, Gomez G, Rigotti A, Cortes LY, Herrera-Cuenca M, et al. Latin American study of nutrition and health (ELANS): rationale and study design. BMC Public Health. 2016;16:93.

25. Colley R, Connor Gorber S, Tremblay MS. Quality control and data reduction procedures for accelerometry-derived measures of physical activity. Health Rep. 2010;21:63-9.

26. Trost SG, Loprinzi PD, Moore R, Pfeiffer KA. Comparison of accelerometer cut points for predicting activity intensity in youth. Med Sci Sports Exerc. 2011:43:1360-8

27. Salvo D, Sarmiento OL, Reis RS, Hino AAF, Bolivar MA, Lemoine PD, Gonçalves $P B$, Pratt $M$. Where Latin Americans are physically active, and why does it matter? Findings from the IPEN-adult study in Bogota, Colombia; Cuernavaca, Mexico; and Curitiba, Brazil. Prev Med. 2017;103S:S27-33.

28. Freedson PS, Melanson E, Sirard J. Calibration of the computer science and applications, inc. accelerometer. Med Sci Sports Exerc. 1998;30:777-81.

29. Freedson PS, Miller K. Objective monitoring of physical activity using motion sensors and heart rate. Res Q Exerc Sport. 2000;71(Suppl 2):S21-9.

30. Freedson PS, Lyden K, Kozey-Keadle S, Staudenmayer J. Evaluation of artificial neural network algorithms for predicting METs and activity type from accelerometer data: validation on an independent sample. J Appl Physiol. 2011;111:1804-12.

31. Sasaki JE, John D, Freedson PS. Validation and comparison of ActiGraph activity monitors. J Sci Med Sport. 2011;14:411-6.

32. Cornier MA, Despres JP, Davis N, Grossniklaus DA, Klein S, Lamarche B, et al. Assessing adiposity: a scientific statement from the American Heart Association. Circulation. 2011;124:1996-2019.

33. Onat A, Hergenc G, Yuksel H, Can G, Ayhan E, Kaya Z, Dursunoğlu D. Neck circumference as a measure of central obesity: associations with metabolic syndrome and obstructive sleep apnea syndrome beyond waist circumference. Clin Nutr. 2009;28:46-51.

34. Pesquisa de Orçamentos Familiares (POF) 2008-2009: Antropometria e estado nutricional de crianças, adolescentes e adultos no Brasil. Rio de Janeiro: Instituto Brasileiro de Geografia e Estatística. 2010.

35. Instituto Nacional de Estadística. República Bolivariana de Venezuela, síntesis estadística de pobreza e indicadores de desigualdad. 2011.

36. Asociacion Investigadores de Mercado. Grupos socioeconómicos Chile. Chile: Asociacion investigadores de mercado; 2012.

37. IPSOS. Estudio general de medios; 2012

38. Instituto Nacional de Estadística y Censos de Ecuador. Encuesta de estratificación de nivel socioeconómico; 2011.

39. Departamento Administrativo Nacional de Estadisticas de Colombia. Proyecciones nacionales y departamentales de poblacion 2005-2020, Estudios Postcensales No. 7. 2009.

40. Comisión de Enlace Institucional AAM-SAIMO-CEIM. Nivel Socioeconómico. Antecedentes, marco conceptual, enfoque metodológico y fortalezas. Buenos Aires: Comisión de Enlace Institucional AAM-SAIMO-CEIM; 2006.

41. Associação Brasileira de Empresas de Pesquisa (ABEP). Critério padrão de classificação econômica Brasil; 2013.

42. R Core Team. R: a language and environment for statistical computing. Vienna: R foundation for statistical computing; 2017. https://www.R-project. org/. Accessed 25 June 2018

43. Bates $D$, Maechler M, Bolker B, Walker S. Fitting linear mixed-effects models using Ime4. J Stat Softw. 2015;67:1-48.

44. Filozof C, Gonzalez C, Sereday M, Mazza C, Braguinsky J. Obesity prevalence and trends in Latin-American countries. Obes Rev. 2001;2:99-106.

45. Uauy R, Albala C, Kain J. Obesity trends in Latin America: transiting from under- to overweight. J Nutr. 2001;131:893S-9S.

46. Bautista LE, Casas JP, Herrera VM, Miranda JJ, Perel P, Pichardo R, González A, Sanchez JR, Ferreccio C, Aguilera X, et al. The Latin American consortium of studies in obesity (LASO). Obes Rev. 2009;10:364-70. 
47. Rivera JÁ, de Cossio TG, Pedraza LS, Aburto TC, Sanchez TG, Martorell R. Childhood and adolescent overweight and obesity in Latin America: a systematic review. Lancet Diabetes Endocrinol. 2014;2:321-32.

48. Kelly T, Yang W, Chen CS, Reynolds K, He J. Global burden of obesity in 2005 and projections to 2030. Int J Obes. 2008;32:1431-7.

49. Al Snih S, Graham JE, Kuo YF, Goodwin JS, Markides KS, Ottenbacher KJ. Obesity and disability: relation among older adults living in Latin America and the Caribbean. Am J Epidemiol. 2010;171:1282-8.

50. Schmidt Ml, Duncan BB, Azevedo e Silva G, Menezes AM, Monteiro CA, Barreto SM, Chor D, Menezes PR. Chronic non-communicable diseases in Brazil: burden and current challenges. Lancet. 2011;377:1949-61.

51. Prospective Studie Collaboration, Whitlock G, Lewington $S$, Sherliker $P$, Clarke R, Emberson J, Halsey J, Qizilbash N, Collins R, Peto R. Body-mass index and cause-specific mortality in 900000 adults: collaborative analyses of 57 prospective studies. Lancet. 2009:373:1083-96.

52. Qureshi NK, Hossain T, Hassan Ml, Akter N, Rahman MM, Sultana MM, Ashrafuzzaman SM, Latif ZA. Neck circumference as a marker of overweight and obesity and cutoff values for bangladeshi adults. Indian J Endocrinol Metab. 2017;21:803-8.

53. Aggarwal T, Bhatia RC, Singh D, Sobti PC. Prevalence of obesity and overweight in affluent adolescents from Ludhiana, Punjab. Indian Pediatr. 2008:45:500-2

54. Mason C, Katzmarzyk PT. Variability in waist circumference measurements according to anatomic measurement site. Obesity. 2009;17:1789-95.

55. Pereira PF, Serrano HM, Carvalho GQ, Lamounier JÁ, Peluzio Mdo C, Franceschini Sdo C, Priore SE. Waist circumference as indicator of body fat and metabolic alterations in teenagers: comparison among four references. Rev Assoc Med Bras (1992). 2010;56:665-9.

56. Nafiu OO, Burke C, Lee J, Voepel-Lewis T, Malviya S, Trempe KK. Neck circumference as a screening measure for identifying children with high body mass index. Pediatrics. 2010;126:e306-10.

57. Vasques AC, Rosado L, Rosado G, Ribeiro Rde C, Franceschini S, Geloneze B. Anthropometric indicators of insulin resistance. Arq Bras Cardiol. 2010;95:e14-23.

58. Jensen MD. Lipolysis: contribution from regional fat. Annu Rev Nutr. 1997; 17:127-39.

59. Sjostrom CD, Lissner L, Sjostrom L. Relationships between changes in body composition and changes in cardiovascular risk factors: the SOS intervention study. Swedish obese subjects. Obes Res. 1997;5:519-30.

60. Sjostrom CD, Hakangard AC, Lissner L, Sjostrom L. Body compartment and subcutaneous adipose tissue distribution--risk factor patterns in obese subjects. Obes Res. 1995:3:9-22.

61. Ramirez V, Shokri-Kojori E, Cabrera EA, Wiers CE, Merikangas K, Tomasi D, Wang GJ, Volkow ND. Physical activity measured with wrist and ankle accelerometers: age, gender, and BMI effects. PLoS One. 2018;13:e0195996.

62. Van Dyck D, Cerin E, De Bourdeaudhuij I, Hinckson E, Reis RS, Davey R, Sarmiento OL, Mitas J, Troelsen J, MacFarlane D, et al. International study of objectively measured physical activity and sedentary time with body mass index and obesity: IPEN adult study. Int J Obes. 2015;39: 199-207.

63. Donnelly JE, Hillman CH, Castelli D, Etnier JL, Lee S, Tomporowski P, Lambourne K, Szabo-Reed AN. Physical activity, fitness, cognitive function, and academic achievement in children: a systematic review. Med Sci Sports Exerc. 2016;48:1223-4.

64. Urke HB, Mittelmark MB, Valdivia M. Trends in stunting and overweight in Peruvian pre-schoolers from 1991 to 2011: findings from the demographic and health surveys. Public Health Nutr. 2014;17:2407-18.

65. Loret de Mola C, Quispe R, Valle GA, Poterico JA. Nutritional transition in children under five years and women of reproductive age: a 15-years trend analysis in Peru. PLoS One. 2014:9:e92550.

66. Finucane MM, Stevens GA, Cowan MJ, Danaei G, Lin JK, Paciorek CJ, Singh GM, Gutierrez HR, Lu Y, Bahalim NA, et al. National, regional, and global trends in body-mass index since 1980: systematic analysis of health examination surveys and epidemiological studies with 960 country-years and 9.1 million participants. Lancet. 2011;377:557-67.

67. Stevens GA, Singh GM, Lu Y, Danaei G, Lin JK, Finucane MM, Bahalim NA, McIntire RK, Gutierrez HR, Cowan M, et al. National, regional, and global trends in adult overweight and obesity prevalences. Popul Health Metrics. 2012;10:22.
68. Mielke Gl, Hallal PC, Rodrigues GBA, Szwarcwald CL, Santos FV, Malta DC. Physical activity and television viewing among Brazilian adults. National Health Survey 2013. Epidemiol Serv Saúde. 2015;24:277-86.

69. Vigitel Brasil. Vigilância de fatores de risco e proteção para doenças crônicas por inquérito telefônico. 2014http://bvsms.saude.gov.br/bvs/publicacoes/ vigitel_brasil_2014.pdf. Acessed 25 May 2018.

\section{Publisher's Note}

Springer Nature remains neutral with regard to jurisdictional claims in published maps and institutional affiliations.
Ready to submit your research? Choose BMC and benefit from:

- fast, convenient online submission

- thorough peer review by experienced researchers in your field

- rapid publication on acceptance

- support for research data, including large and complex data types

- gold Open Access which fosters wider collaboration and increased citations

- maximum visibility for your research: over $100 \mathrm{M}$ website views per year

At BMC, research is always in progress.

Learn more biomedcentral.com/submissions 